\title{
Use of an Intravitreal Dexamethasone Implant (Ozurdex) in a Case with Accidental Foveal Photocoagulation by Alexandrite Laser
}

\author{
Muhammed Nurullah Bulut Ümit Çallı Eren Göktaş Kezban Bulut \\ Baran Kandemir Yusuf Özertürk \\ Eye Department, Dr. Lütfi Kırdar Kartal Education and Research Hospital, Istanbul, Turkey
}

Key Words

Alexandrite laser $\cdot$ Ozurdex $\cdot$ Macular edema

\begin{abstract}
Alexandrite laser is one of the most common methods of hair removal. Its utilization is gradually increasing due to easy accessibility and high effectiveness. However, the disuse of protective goggles during the application of this laser is a serious problem. In this case report, we presented a 35-year-old male patient who had foveal injury by alexandrite laser. The inflammatory process secondary to the foveal injury and subsequent macular edema were treated with Ozurdex because of its potent antiedematous effect.

(C) 2016 The Author(s)

Published by S. Karger AG, Basel

\section{Introduction}

Alexandrite laser $(755 \mathrm{~nm})$ is one of the most common methods of hair removal. Its utilization is gradually increasing due to easy accessibility and high effectiveness. However, the disuse of protective goggles during the application of this laser is a serious problem. Alexandrite laser light is visible, and it is known that ocular injuries may occur during the use of alexandrite laser when protective goggles are not worn [1,2]. Still, foveal injuries by alexandrite laser are rare. Herein, we reported a case with accidental foveal injury and subsequent macular edema secondary to alexandrite laser contact, treated with an intravitreal Ozurdex implant.
\end{abstract}

\section{KARGER}

Muhammed Nurullah Bulut

Eye Department, Dr. Lütfi Kırdar Kartal Education and Research Hospital

Denizer Cad. E-5 yanı Cevizli-Kartal

TR-34860 Istanbul (Turkey)

E-Mail nurullahbulut@ hotmail.com 
Bulut et al.: Use of an Intravitreal Dexamethasone Implant (Ozurdex) in a Case with Accidental Foveal Photocoagulation by Alexandrite Laser

\section{Case Presentation}

A 35-year-old male patient presented to our clinic complaining of a scotoma in the right eye, which had begun $2 \mathrm{~h}$ after looking at a laser probe for a few seconds in an esthetics clinic. The patient underwent full ophthalmic examination. Best corrected visual acuity (BCVA) was 10/10 in both eyes. Anterior segment examination was unremarkable. Fundus examination showed a pale, white and sharply circumscribed laser spot lesion localized at the inferior nasal foveal region, involving the central foveola. A visual field test (Humphrey, Zeiss, Germany) displayed a scotoma consistent with the affected region. A hypofluorescent lesion, which was in accordance with the round laser spot, was detected in the early and late phases of fundus fluorescein angiography (Canon Inc., Tokyo, Japan). An intense increase in reflectance in the region of the spot was also identified on optic coherence tomography (OCT; SLO, Optos, Dunfermline, UK). All examinations of the left eye were unremarkable. A topical steroid was chosen as initial treatment.

There was no change in the findings at the first control visit after 1 week. However, at the second week, the BCVA of the patient had decreased to $3 / 10$, and edema and hemorrhage had occurred around the lesion. OCT demonstrated intra- and subretinal edema as well as tissue disruption within the injured area (fig. 1). Thus, intravitreal Ozurdex (Allergan, Inc., Irvine, Calif., USA) therapy was decided on, based on its rapid antiedematous effect.

Ozurdex was implanted via the pars plana region with its specific cartridge in the operating room. Topical antibiotics were given after the injection. BCVA increased to 4/10, 1 week after the injection. An intraocular pressure elevation (35 mm Hg) which was successfully controlled by a topical antiglaucomatous agent occurred.

One month after the injection, BCVA was 20/30 despite a hemorrhage around the injured area on fundus examination (fig. 2). At month 3, BCVA had increased to 20/20. OCT showed decreased macular edema and a hyperreflectance scar in the affected area (fig. 3 , fig. 4). A visual field test demonstrated no change in the scotoma of the patient.

\section{Discussion}

It is known that alexandrite laser causes a temperature increase and subsequent coagulation necrosis in melanin-containing tissues, which is termed 'selective photothermolysis' [3]. This temperature rise might cause burns, pigmentation changes, and erythema in surrounding tissues [4]. There are two types of eye injuries associated with alexandrite laser. The first type are anterior segment complications such as uveitis, pupillary distortion [1], iris atrophy [2], and cataract, which can occur due to laser applications to the face with closed eyes. The second type are posterior segment complications such as macular hole [5] and macular scar [6] caused by the direct effect of the laser beam on the retina while the eyes are open.

The Ozurdex intravitreal implant is composed of a biodegradable copolymer of lactic and glycolic acids containing micronized dexamethasone [7]. The drug-copolymer complex gradually releases dexamethasone that transforms into glycolic and lactic acids after the injection and eventually into water and carbon dioxide [8]. After intravitreal injection, the Ozurdex implant reduces the vitreous levels of several mediators which cause disruption of the blood-retinal barrier (i.e., vascular endothelial growth factor) and accordingly diminishes the vascular permeability. Ozurdex is frequently used in the treatment of macular edema due to diabetes mellitus, retinal vein occlusion, and noninfectious uveitis. 
Bulut et al:: Use of an Intravitreal Dexamethasone Implant (Ozurdex) in a Case with Accidental Foveal Photocoagulation by Alexandrite Laser

In our case, we first used topical steroid drops to prevent complications after alexandrite laser injury; however, this medication was ineffective. Therefore, the inflammatory process secondary to the foveal injury and the subsequent macular edema were treated with Ozurdex because of its rapid and potent antiedematous effect. In a case report by AnayaAlaminos et al. [6], BCVA was reported as 20/200 initially and 20/100 after a 1-year followup period in a patient with accidental foveal injury by alexandrite laser. There was no information about the treatment or whether macular edema had occurred during the follow-up period. We believe that the better final visual acuity in our case was achieved by swift resolution of macular edema by Ozurdex.

Retrobulbar and oral steroid treatments have been used in the treatment of foveal injuries caused by femtosecond laser and green laser pointer $[9,10]$. BCVA improved from $20 / 30$ to $20 / 20$ after treatment in a case with femtosecond laser injury [9], while it increased from $20 / 100$ to $20 / 60$ in a case with green laser pointer injury [10]. The difference between the initial visual acuities and their increases might have been caused by the different energy levels, the durations of laser contact, and the distances of the lesions from the central foveola. The response to treatment was often greater among eyes with a shorter duration of macular edema [7]. We preferred an Ozurdex implant to systemic steroids due to its rapid and target-oriented effect and the lower systemic side effects for reducing macular edema. In summary, alexandrite laser injuries might cause macular injury and edema, and the Ozurdex implant can be an effective treatment in these cases.

\section{Statement of Ethics}

The patient was informed about the risks of the treatment, and informed consent was obtained.

\section{Disclosure Statement}

None of the authors report any conflicts of interest with this submission.

\section{References}

1 Lin CC, Tseng PC, Chen CC, Woung LC, Liou SW: Iritis and pupillary distortion after periorbital cosmetic alexandrite laser. Graefes Arch Clin Exp Ophthalmol 2011;249:783-785.

-2 Elkin Z, Ranka MP, Kim ET, Kahanowicz R, Whitmore WG: Iritis and iris atrophy after eyebrow epilation with alexandrite laser. Clin Ophthalmol 2011;5:1733-1735.

3 Wanner M: Laser hair removal. Dermatol Ther 2005;18:209-216.

4 Hammes S, Karsai S, Metelmann HR, Pohl L, Kaiser K, Park BH, et al: Treatment errors resulting from use of lasers and IPL by medical laypersons: results of a nationwide survey. J Dtsch Dermatol Ges 2013;11:149156.

5 Lin LT, Liang CM, Chiang SY, Yang HM, Chang CJ: Traumatic macular hole secondary to a Q-switch alexandrite laser. Retina 2005;25:662-665.

-6 Anaya-Alaminos R, Muñoz-Ávila JI, González-Gallardo MC, Mora-Horna ER, García- Serrano JL, RamírezGarrido MV: Accidental foveal photocoagulation secondary to alexandrite laser. Eur J Ophthalmol 2014;24:808-810.

7 Haller JA, Bandello F, Belfort R Jr, Blumenkranz MS, Gillies M, Heier J, et al; Ozurdex Geneva Study Group: Randomized, sham-controlled trial of dexamethasone intravitreal implant in patients with macularedema due to retinal vein occlusion. Ophthalmology 2010;117:1134-1146. 
Case Reports in

Ophthalmology

\begin{tabular}{l|l}
\hline Case Rep Ophthalmol 2016;7:130-134 \\
\hline DOI: 10.1159/000444077 & $\begin{array}{l}\text { ○ 2016 The Author(s). Published by S. Karger AG, Basel } \\
\text { www.karger.com/cop }\end{array}$ \\
\hline
\end{tabular}

Bulut et al:: Use of an Intravitreal Dexamethasone Implant (Ozurdex) in a Case with Accidental Foveal Photocoagulation by Alexandrite Laser

-8 Chang-Lin JE, Attar M, Acheampong AA, Robinson MR, Whitcup SM, Kuppermann BD, et al:

Pharmacokinetics and pharmacodynamics of a sustained-release dexamethasone intravitreal implant. Invest Ophthalmol Vis Sci 2011;52:80-86.

-9 Yang X, Jiang F, Song Y: Accidental macular injury from prolonged viewing of a plasma flash produced by a femtosecond laser. Ophthalmology 2010;117:972-975.

10 Lim ME, Suelzer J, Moorthy RS, Vemuri G: Thermal macular injury from a $154 \mathrm{~mW}$ green laser pointer. J AAPOS 2014;18:612-614.

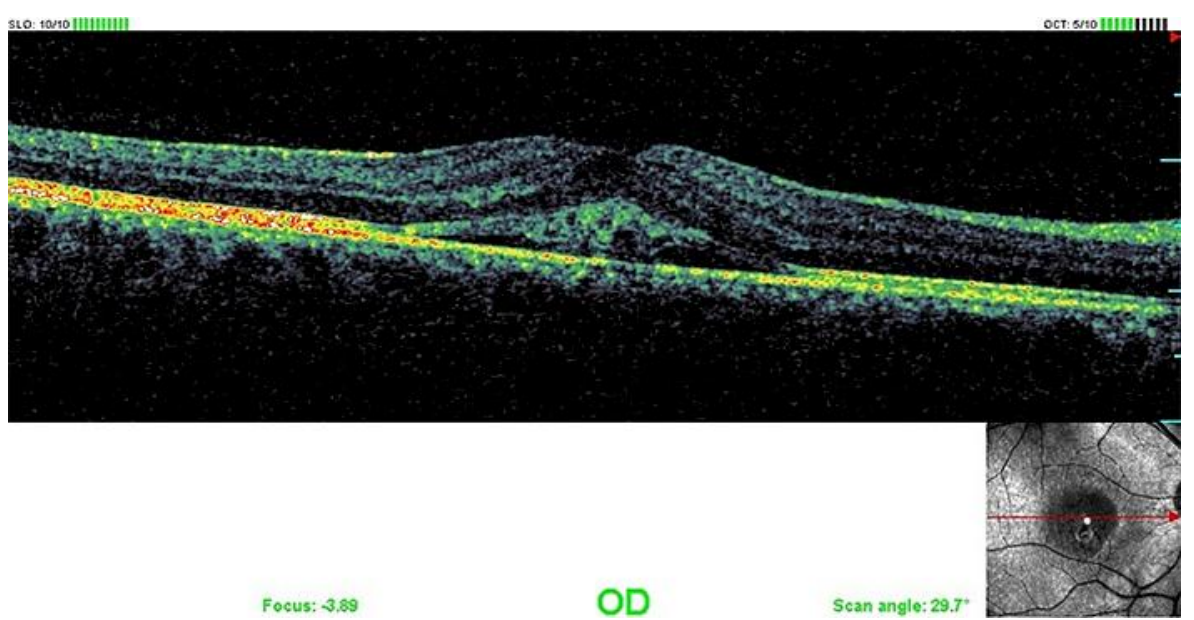

Fig. 1. Intra- and subretinal edema and hyperreflectance due to tissue disruption in the laser spot area.

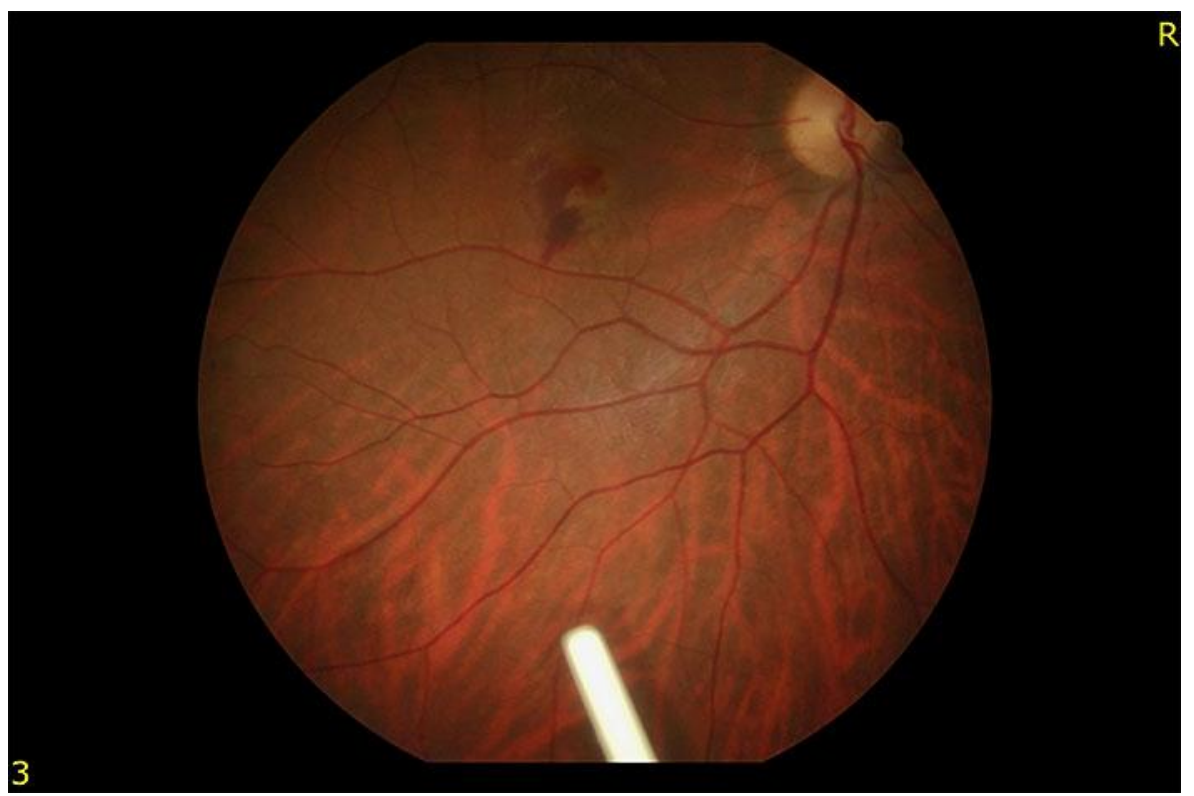

Fig. 2. Hemorrhage around the spot and the Ozurdex implant on fundus examination. 
Case Reports in

Ophthalmology
Case Rep Ophthalmol 2016;7:130-134

DOI: $10.1159 / 000444077$

(C) 2016 The Author(s). Published by S. Karger AG, Basel www.karger.com/cop

Bulut et al.: Use of an Intravitreal Dexamethasone Implant (Ozurdex) in a Case with Accidental Foveal Photocoagulation by Alexandrite Laser

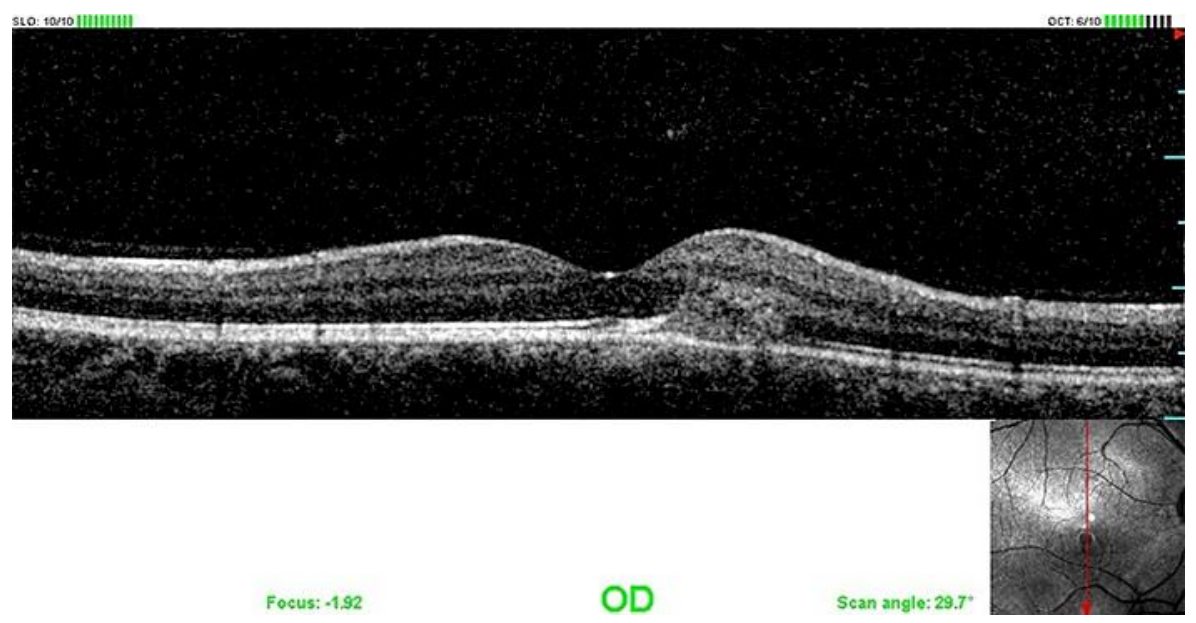

Fig. 3. OCT image shows hyperreflectance scar in the affected region at the second month after Ozurdex implantation.

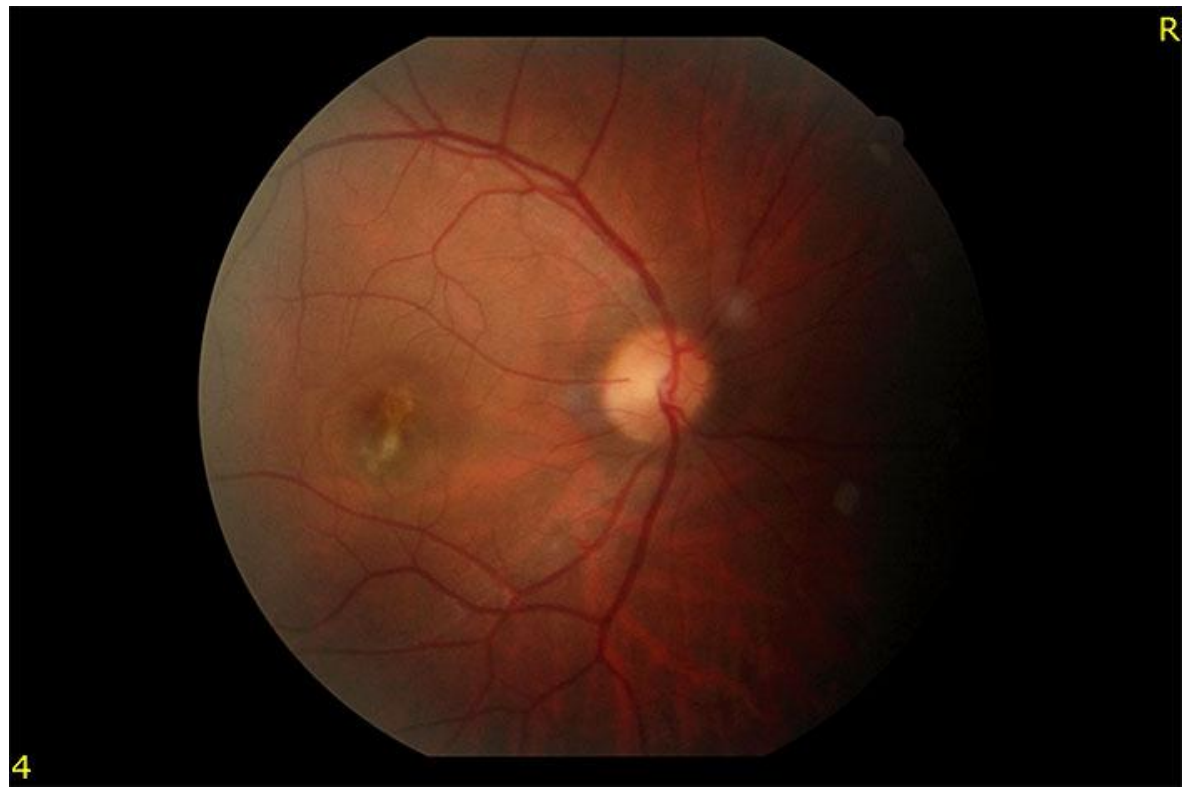

Fig. 4. Fundus photograph after treatment. 